\title{
Engaging Theatre, Activating Publics: Theory and Practice of a Performance on Darwin
}

\author{
SAUL E. HALFON \\ VIRGINIA TECH \\ CORA OLSON \\ VIRGINIA TECH \\ ANN KILKELLY \\ VIRGINIA TECH \\ JANE L. LEHR \\ CAL POLY
}

\begin{abstract}
The Theatre Workshop in Science, Technology and Society (TWISTS) is a unique public engagement project. Theoretically, TWISTS seeks to activate publics around contemporary science and technology issues by producing agonistic cultural spaces in which participants are confronted with and engaged by multiple perspectives. It thus seeks to enact a model of Public Engagement with Science and Technology (PEST) that is oriented toward neither individualized educational models nor policy deliberation and consensus. Its engaged STS performance model instead merges expanded notions of expertise with challenges and techniques derived from critical performance theory, such as recentering participants, rethinking purpose and evaluation, and reworking narrative structure. Practically, TWISTS' four existing performance cycles have been sites for both extending and challenging the theory. Using a unique system of expert interviews, writing, and theater games, these performances were collaboratively derived by a range of participants. The "Living Darwin" performance serves as a case study for exploring the tensions of this collaboration. Negotiating a set of different perspectives over the place of Darwin in contemporary life, and the proper way to represent him and his influence, was challenging, but proved productive in developing a performance that raised these issues for the audience within an agonistic space.
\end{abstract}

Saul E. Halfon, Email: shalfon@vt.edu

2Cora Olson, Email: cowebb@vt.edu

${ }^{3}$ Ann Kilkelly, Email: akilkell@vt.edu

Jane L. Lehr, Email: jlehr@calpoly.edu

Copyright (c) 2020 (Saul E. Halfon, Cora Olson, Ann Kilkelly, Jane L. Lehr). Licensed under the Creative Commons Attribution Non-commercial No Derivatives (by-nc-nd). Available at estsjournal.org. 


\section{Keywords}

performance; public engagement; agonism; expertise; Darwin

\section{Introduction}

Discussions in this journal and elsewhere have raised the question of how Science and Technology Studies (STS) might engage more fully non-STS audiences and institutions (Kleinman and Vann 2016; Zuiderent-Jerak and Jensen 2007). The range of responses to this question is quite broad, and rightly so (Rowe and Frewer 2005). There is no best way to practice what is increasingly known as "engaged STS" (Downey \& Zuiderant 2016).

Formalized approaches to public engagement include mechanisms like consensus conferences and public forums (Wilsdon and Willis 2004). Professional engagement includes collaborations and studies that attempt to push other fields and professional practices to be more fully reflective about knowledge, social meaning, and techno-sociality (Fisher and Mahajan 2010; Fisher, Mahajan, and Mitcham 2006). Interventions into daily life include blogs and op-eds as well as participating in social movements and theorizing around embodied experience (Cohen and Galusky 2010; Woodhouse et al. 2002).

This paper explores and reflects on an approach to STS engagement that is quite different from those reported previously in the literature. The Theater Workshop in Science, Technology, and Society (TWISTS) draws on critical performance theory to rethink both the theory and practice of public engagement, as well as its practical goals. While part of both the science theater movement and the Public Engagement with Science and Technology (PEST) movement, this project is unique in both arenas in that it integrates critical STS insights about expertise, knowledge, power, and culture with insights and practices from critical performance theory about performance, representation, community engagement, and the body (Schechner 1988).

The paper explores the central question: can a University-based, agonistic performance model succeed in activating a community to grapple with complex S\&T issues? Or, put more simply, does TWISTS serve a meaningful function as public engagement beyond the aesthetic enjoyment of participants? And, does it offer a model of PEST that hues more closely to that movement's stated ideals? In response to such questions, we offer a tempered optimism.

In what follows, we develop first the theory and then the practice of TWISTS. The theory builds a performance-based STS engagement model that takes as its goal agonistic community engagement with controversial science and technology issues (Mouffe 2000). Agonism, as described by Chantal Mouffe, is a form of dialogic democracy that refrains from the erasure of counter-hegemonic, subjugated, or unpopular perspectives. In this sense, agonism names a space for productive conflict (as opposed to simple antagonism) in which opponents are challenged to recognize and acknowledge, though not accede to, positions and perspectives different from their own: "antagonism is struggle between enemies, while agonism is struggle between adversaries" (Mouffe 2000: 103). The focus for TWISTS is thus on transformation of both self-perception and interactions within communities, through practices of discomfort, encounter, and dialog among multiple perspectives and forms of knowledge. 
In describing the practice, we focus on the October, 2009, performance of "Living Darwin." Staged over 4 nights, with over 600 people in attendance, this performance was developed over the previous year by TWISTS. As part of the Darwin Year, the 200" birthday of Charles Darwin and 150" anniversary of On the Origin of Species, "Living Darwin" was our attempt to explore the relevance of Darwin's thought and legacy for contemporary lives-to both challenge and valorize a key feature of contemporary thought. The TWISTS model and "Living Darwin" performance provide the site for a complex negotiation of STS engagement "on the ground."

\section{Theorizing TWISTS}

TWISTS began, not as a concept, but as a practice. It emerged from several years of theatrical engagement through the venue of the Choices and Challenges public science forums, which have been held at Virginia Tech for the past 30 years (candc.sts.vt.edu). Choices and Challenges seeks to engage public audiences in dialog about contemporary science and technology issues, but largely through expert-led sessions and panels.

The performances seemed to offer a different model of engagement--one more in line with emerging theory in STS, education, and related fields, which treat contemporary public controversies as conflicts over values and worldviews, rather than conflicts caused by a lack of knowledge (Davies et al. 2009; Irwin and Wynne 1996; Lehr et al. 2007; Wilsdon and Willis 2004). Performances offered the opportunity to engage publics in active meaning-making rather than expert-led reception of information (Leach and Scoones 2006). Several people involved in Choices and Challenges spun TWISTS off as a parallel, but separate effort. ${ }^{5}$ TWISTS itself has now wound down and is no longer actively creating events, although Choices and Challenges continues.

From the start, TWISTS' strong connection to both critical STS and critical performance practice was central to how the project was conceived, and this particular configuration has helped to distinguish TWISTS from other "science theater" projects, such as those described by Kirsten Shepherd-Barr (2006), who notes that the bulk of recent science plays "utilize scientific ideas or feature scientists as their center" (1), but are rarely informed by an STS-oriented critical approach to knowledge, authority, expertise, and voice (however, see Sullivan et al. (2008), Cless (1996), and The Y-Touring Theatre Company of London).

\footnotetext{
${ }_{5}^{5}$ Jane Lehr, then an STS graduate student, founded this new effort, and was joined initially by: STS scholars Saul Halfon, Cora Olson, Sharon Elber, Barbara Reeves, Deanna Spraker, and Robert Olivo; Performance scholars Ann Kilkelly, Drew Dowdy, Kristin Shumaker, Megan Carney, Shannon Turner \& Gary Wood; Education scholar Carol Brandt; and Playwright Alice Shen. A number of other collaborators moved through the project over the following years. Initial activities were funded by a startup grant from Virginia Tech's Institute for Society, Culture, and the Environment.
} 


\section{Extending PEST}

TWISTS embodies and enacts lessons and theorizing emerging from the Public Engagement with Science and Technology (PEST) movement, a term formulated in Britain in the early 2000's (Sainsbury and Dexter 2000; Holden 2002). PEST articulates an attitude of mutual learning in science/public interactions (McCallie et al. 2009, 24), diverging definitively from the public deficit model of earlier Public Understanding of Science approaches, and vacillating between either a deliberative or more radical model of interaction. It articulates a notion of scientific citizenship that accounts for the uncertainties and cultural embedding of scientific knowledge (Irwin 2001; Elam and Bertilsson 2003; Jasanoff 2004; Lehr 2006; Lengwiler 2008; Nowotney, Scott, and Gibbons 2001).

TWISTS offers a new model of such public engagement--serving as a forum where "active citizen engagement with science and technology" can "be worked on, and learned" (Leach and Scoones 2006, 59). In particular, it rejects either the policy or educational orientation of many such projects, emphasizing instead a cultural politics of engagement.

\section{From Policy Consensus to Agonistic Engagement}

Our orientation is thus on mutual learning and engagement, rather than policy, as such. Many of the STS-oriented public engagement projects reported in the literature-models such as consensus conferences and technology assessment--have an explicit focus on policy outcomes. We see this in both the conceptualization of these projects and in various attempts to measure outcomes and success. While bringing citizens into policymaking is an important goal, it is difficult to achieve in practice and often has a minimal effect on policy itself, particularly in the United States. US scholars in particular have had to stretch to find hope and second-order successes in those projects that have been assessed and reported (Guston 1999; Sclove 2000). More recent policy-oriented literature has developed promising approaches, such as linkage to existing policy networks (Delborne et al. 2013) and integration of citizen engagement into existing decision-making systems (Sclove 2010). However, Pestre (2008) suggests a range of reasons that policy-oriented engagement projects are problematic in general, and we made an early decision to forgo a policy orientation because of the constraints it placed on enacting cultural practices of public engagement.

Moving away from a policy orientation has several implications. First, we have no need for "consensus" outcomes. Most approaches to public engagement involve some appeal to consensus, particularly consensus built on dialogic rationalism (Einsiedel and Eastlick 2000; Einsiedel, Jelsøe, and Breck 2001; Joss and Durant 1995; Mayer and Geurts 1999; Rip, Misa, and Schot 1995; Rowe and Frewer 2005; Dryzek 2000). TWISTS commits instead to performance and the right of citizen dissent, thereby revealing and humanizing tensions, incommensurabilities,

and difference while also articulating connections and commonalities. We seek to bridge to the non-dialogic aspects of culture and communication without reduction to agreement. 
Second, we do not need to fix what counts as relevant forms or terms of expertise for decisionmaking. While we can never remain fully agnostic about expertise in a particular case, since we do have to organize events and invite participants, this reflexive, theoretically informed, approach to expertise and knowledge does provide an opportunity to be much more inclusive than may be possible in other settings.

Third, eschewing policy goals allows us to move towards a radical democratic politics of mobilizing agonisms-that is, a politics of discomfort-while using theatrical engagement to overcome common tendencies to avoid direct conflict and socially awkward disagreements (on the former, see Mouffe 2000; on the latter, see Mutz 2006). As the Greek "agon" designated a structured place of irresolvable confrontation and forms the central scheme for many western dramas, so agonism provides a framework for imagining productive conflict in Democratic politics: "agonism implies a deep respect and concern for the other; ... an agonistic discourse will therefore be one marked not merely by conflict but, just as important, by mutual admiration" (Chambers 2001). Rather than favoring settings oriented toward deliberative consensus building, we seek to create settings for engaging in creative and productive discomfort and dissent (Boler 1999).

This agonistic goal suggests a unique approach to both project form and content. Our form is derived from the theatrical techniques of Augusto Boal in particular, which we use extensively in performance development, attempting to break us out of the cultural scripts embedded within our bodies and to awaken tensions, towards action and justice (see discussion below, also Boal 1979/1982;1992). Our content is viewed as a set of challenges to hegemonic positions, of equalizing positions or highlighting the power that accompanies their inequality, and of making visible, or authorizing, voices that are not clearly in focus within public settings (e.g., Harding 2006; Haraway 1988). These goals have deep roots in both STS and art, which is why this form of collaboration is so promising, but they are often difficult to realize in practice when dealing with ongoing science and technology controversies.

Project success from this perspective is gauged not by the audience experience of the performance itself (whether they "like," "agree with," or "understand" the performance) but by ongoing engagement with the performance and its ideas in its aftermath, focusing on individual and group outcomes rather than achieving consensus or agreement. We do not offer the audience a singular perspective, but rather recognize and grapple with a full range of perspectives in their human and cultural context, seeking to clarify knowledge as perspectival and situated, and to reveal its situation while simultaneously making visible multiple perspectives. Performance has the possibility of making perspectives visible viscerally and humanely, such that opposing positions need not be agreed with, but can neither be ignored nor simply written off. This ethos, developed further in what Connolly $(2005 ; 2008)$ has called "critical responsiveness," underlies agonism (Mouffe 2000). 


\section{Mutual Learning and the Multiplicity of Expertise}

The project's frame of mutual learning and activating public grappling with controversial science and technology works against most explicitly educational public engagement projects, which all too often take a teleological stance towards knowledge, providing a set of facts, ideas, or approaches that audiences are encouraged to take on as their own. Even discovery-based or student-led learning environments rely heavily on expert-defined goals (Lehr 2006; Davies et al. 2009; Davies 2014). While this form of education has its place, it poorly responds to STS inspired PEST critiques of knowledge, power, and expertise (Irwin 2001; Irwin and Wynne 1996; Irwin 2014).

By "mutual learning" we have in mind de-centering the authority of scientists in sciencepublic exchanges and facilitating instead relationships in which all participants learn from and come to understand each other: "the idea of mutual learning and reflective exchange, ... is a core premise of the upstream engagement proponent's claim for a more democratic involvement" (Kurath and Gisler 2009; see also: Davies et al. 2009; Wilsdon and Willis 2004). Issues of power, hierarchy, and authority are central considerations in conceptualizing mutual learning. We use this notion to emphasize not just mutual learning between scientists and the public, but also learning among various publics through the embodiment and confrontation of multiple voices.

In exploring contemporary public controversies as conflicts over values and worldviews, rather than conflicts caused by a lack of knowledge (Davies et al. 2009; Irwin and Wynne 1996; Lehr et al. 2007; Wilsdon and Willis 2004), and understanding socio-scientific controversies as the outcome of multiple, competing perspectives that can be strongly supported, TWISTS projects require a critical approach to both knowledge and expertise, with a commitment to multiple perspectives and forms of knowledge. A primary question for TWISTS collaborators is how to garner such a range of perspectives and portray them adequately in a performance that also answers to artistic, aesthetic, and narrative demands.

TWISTS does not reject or avoid the category of expertise, but rather extends this notion in line with recent discussions in STS. In Evans and Collins' (2008) terms, it recognizes the proliferation of relevant specialist expertises (including specialist contributory expertise-"traditional expertise") within a controversial issue, but also recognizes that technical expertise cannot map out the entire relevant space for sense-making. Specialist expertise becomes conversational with ubiquitous, everyday forms of expertise within our development workshops and performances.

This approach addresses Evans and Collins' $(2008,614)$ concern: rather than opening decision-making as broadly as possible, such that lay citizens displace experts at every point, we acknowledge different and competing forms of expertise relevant to the given issue. Our task as STS scholars developing performances is to deliberately expand, at every moment, what might seem to be the relevant sorts of expertise for various communities that participate. Thus, the TWISTS model aspires to be a way of recognizing the significance of expertise, without unduly valorizing specific forms of knowledge (Liberatore \& Funtowicz 2000). 
In other words, this project seeks to apply the notion of agonism not only to belief, but also to knowledge, and thus to expertise. We draw upon but radically expand the notion of who counts as an expert and what counts as expertise in the S\&T issues we are exploring. Our practice, therefore, is one of drawing together radically divergent forms of knowledge and placing them in direct conversation and encounter.

\section{STS Performance Towards Political Engagement}

Performance has increasingly been recognized as a powerful way of framing complex ideas for public dialogue and student education in an accessible manner (Tselfes and Paroussi 2009; Leonard and Kilkelly 2006; Pearson and Holligan 2002). Combining cognitive, affective, and active learning, performance provides an opportunity to engage the complexity of individual relationships with science and technology, thereby facilitating a move from an educational model of learning scientific facts to one of grappling with science-technology-society relationships (McKibben 2005; Odegaard 2003).

Public engagement scholars Leach and Scoones (2006) suggest that "stimulating active citizen science engagement, involves building the capacity of citizens for presenting and negotiating perspectives... Such reflections emerge most effectively when people are exposed to others' views and lived experiences" (59-60). Performance is an ideal medium for making competing and sometimes contradictory perspectives on socio-scientific issues visible and accessible--providing resources for audience members to understand and express their own perspectives on socio-scientific issues, as well as the perspectives of others.

The approach to performance adopted by TWISTS mirrors our theoretical stance towards science, technology, knowledge, and expertise, and seeks to develop a specifically STS performance theory. It builds on and contributes to a small but persistent STS literature on the importance of performance in generating public support and credibility (Ezrahi 1990; Hilgartner 2000), constructing public audiences (Delborne 2011), and practicing medical sciences (Mermikides and Bouchard 2016). Our vision of the role of performance in stimulating and facilitating public dialogue draws heavily from the frameworks and techniques of devised and collaborative theatre (Bicât and Baldwin 2002; Oddey 1996) and "theatre of the oppressed" (Boal 1979/1982; 1992; Schutzman and Cohen-Cruz 1994; 2006). We are particularly informed by theories and practices in community-based theatre (Leonard and Kilkelly 2006; Rohd 1998), which articulates a set of values and methodologies built around respect for the local and placebased knowledge of communities and the inclusion of community members in arts practices.

Building on such performance theory and theater techniques, TWISTS practice seeks to alter the traditional positions of actors and audiences, thereby multiplying the range and power of voices and perspectives represented in performances. By disrupting dominant spectator positions (Dolan 1988), the male gaze (Mulvey 1975), and the traditional demarcation between actors and spectators (Boal 1979/1982), the TWISTS performance model melds strongly with STS commitments to perspectival knowledge (Haraway 1991, p183-202; Harding 1993) and multiple forms of expertise (Evans and Collins 2008). 
This disruption of performance hierarchies begins in our performance development phase where content experts and other non-professional actors work with theatre experts, using devised and collaborative theatre techniques, including improvisational games, movement, storytelling, and writing, to generate potential performance content (Oddey 1996; Heddon and Milling 2006, p116-122). Such techniques are powerful methods for de-centering the "author" and the "actors" and introducing multiple perspectives, although they present challenges for the coherence and integrity of the final performance.

The various sources of TWISTS' performance model share a concern to develop new forms of audience engagement that make theater more directly connected to everyday life and political struggles, and open the possibility for theater to spur political action. Boal's (1979/1982) forum theatre techniques, for example, draw explicitly from the work of Paulo Friere (1970) to develop a "theatre of the oppressed." Originally developed as part of a literacy program in Peru, and then transferred to engage residents in the poor slums of Rio de Janeiro, Boal used a number of performance techniques-the joker, the spect-actor, Forum theatre, Image theatre, and simultaneous dramaturgy--that prompt participants to not only articulate grievances, but to enact solutions. As Boal moved from communities in the global South to communities in the global North, his goals and techniques changed, but he retained the central premise of activation - practicing potential solutions to off-stage conflicts. TWISTS takes inspiration from that approach, while not relying strictly on "theatre of the oppressed." That is, TWISTS treats theatre as a space where "spect-actors" (an elision of spectator and actor roles) and publics/community members can be activated to wrestle with, propose solutions to, and define problems relating to the multiple perspectives engaged in the contemporary or controversial scientific or technological content at hand.

This project is thus in line with a long-standing performance literature that re-theorizes the meaning and purpose of theater, from entertainment to a space of cultural politics--theatre, devised with communities, that seeks to facilitate change (Heddon and Milling 2006).

\section{Practicing TWISTS}

TWISTS, while theorized, is a practice, in the world. The practice of this project involves a complex series of workshops and performances with a fluid, interdisciplinary group of collaborators. When we talk about the "TWISTS Model" we invoke both the conceptual apparatus that informs TWISTS and the set of practices that we replicate (with modification) through each cycle of performance development and staging. This "test" of the theory (that is, the encounter of theory and practice) highlights the tensions and difficulties of such a project, but offers some hope.

A new TWISTS performance begins with a series of workshops that borrow from Y- 
Touring Theater Company's development model (using expert interviews), STS theories of expertise (expanding beyond traditional notions of expertise), and forum and devised theater techniques (techniques that work with the experiences and bodies of the participants to generate performance content).

A typical multi-day development workshop involves a series of sessions that build knowledge and content. These begin with "expert sessions" in which a range of experts (both credentialed and non-credentialed) are first interviewed by TWISTS collaborators and then creatively engaged in performance activities. Performance activities include a range of techniques accumulated by Ann Kilkelly from Augusto Boal, Maddy Schutzman, and Celeste Miller, among others. They include sociometry, gestural theater, story circles, writing, singing, forum theater, and scene production. Through these techniques, we generate facts, positions, and perspectives along with personal stories, performance images, and scenes.

These performance elements are then iteratively developed into a performance script through subsequent workshops and smaller working sessions among TWISTS collaborators. The final version of the performance is developed with the cast itself using techniques of derived theater (Bicât and Baldwin 2002; Heddon and Milling 2006). The process is messy and difficult and requires the steady hands of an experienced performance developer. In some ways it is precisely at this stage that we run into issues of the reproducibility and sustainability of the project; that is, the model itself is very much located within the experiences of particular collaborators. This raises tensions between the localization of the project-a strong goal of all TWISTS work-and the desire to "scale up" TWISTS as a model for public engagement with science and technology (Downey 2009).

As the script is largely developed in the hands of our artistic director, it has become obvious that our individual and collective expertise shapes and locates this project and model as "local." For those of us who are STS practitioners, the script development process can involve fraught negotiation, because we are cast simultaneously as outsiders (performance non-experts) and insiders (content and TWISTS model experts) to this process. Ideally, the located-ness of this project does not preclude the implementation of similar projects elsewhere. What is crucial in the development and scaling up of TWISTS-like projects is establishing the theoretical and practical commitments of the collaborators. There is no reason why other groups cannot be formed with a similar commitment to agonism and public activation, but drawing on different techniques and areas of expertise.

Performances are of two types: staged performance-dialogs and interactive performanceworkshops. Performance-dialogs involve fully staged performances (with props, lighting, and sound), lasting an hour or so, followed by a facilitated discussion with the audience. The discussion is not conceived as a typical theater "talk-back," with a focus on the playwright, director, performers, and the process of producing the show; rather, this dialog is conceived as an

\footnotetext{
'An early inspiration for the development of expert workshops in the performance development process was Y-Touring, an innovative and well-known theater troupe in London that stages plays around controversial science and technology issues, followed by audience dialog (see www.theatreofdebate.co.uk).
} 
opening to a community conversation about the issues on the table: about psychiatric drug use, or food ontologies, or nuclear power, or Darwinism in contemporary life (these are the four topics we have engaged). "Nuclear Power Play" was performed this way to about 300 audience members in 2008, and "Living Darwin" to over 600 in 2009.

Performances developed through and faithful to the techniques described above often deviate from traditional narrative structures. With a focus on multiplicity, perspective, and open meanings, straight lines are difficult to maintain. Instead, TWISTS performances weave together and set against each other a range of perspectives and experiences, built around core themes.

As part of a commitment to alternative, non-verbal modes of learning and experience, these performances also emphasize movement, sound, and visual arts. Through collaborations with artists such as dancer-educator Celeste Miller (www.celestemiller.com) and vocalist Elise Witt (elisewitt.com), as well as resident artists such as Carol Burch-Brown (www.carolburchbrown.com) and Ico Bukvic (ico.bukvic.net), TWISTS performances build in a recognition of the intertwining of emotions, bodies, and intellect. For example, Celeste Miller's work, which played a central role in the "Living Darwin" performance, relies on the juxtaposition of text and movement to break hegemonic frames of understanding and to produce new insights that exist outside of either the text or movement alone.

Workshop-performances, staged either before or after the full performance, are a deconstructed version of the performance, melding the methods of performance and development workshops in public settings. Essentially, we enter a setting with scripted scenes and combine those with interactive workshop techniques--mixing performance, participation, and dialog. These workshops are conceived as mobile, flexible, and interactive, allowing direct and repeated audience participation and direction. This sort of staging sits at the heart of the TWISTS conceptualization: it is the moment of direct engagement with the larger community, providing the best venue for the sort of mutual learning and activation that the project aspires to. It is also the most difficult part to carry out given practical constraints, and we held only a few. We held two workshop performances of "Nuclear Power Play" in 2008, two for "Living Darwin" in 2009, and one for our fourth project on local/global food in 2011. Altogether, these performance-workshops reached approximately 130 audience members.

\section{Enacting "Living Darwin"}

The choice of "Darwin" as a topic for contemporary engagement may seem odd, but it was a deliberate response to a local opportunity. A larger university initiative around the "Darwin year" provided visibility, resources, and an ongoing public discourse about Darwin, and the collaborators were aware of the broad set of possibilities in this topic, to bring issues of naturalization and justice to a technologically sophisticated audience interested in evolution, the Great Man, or science in general. Unlike our previous two performances, pertaining to antidepressants and nuclear power, which were more deliberately chosen to respond to issues that had ongoing relevance to the local community, the selection of Darwin as a topic did not emerge out of a clear identification of local concerns. While several of our collaborators were personally 
inspired by Darwin himself, and many of us saw important opportunities in the topic, we began the process without a clear sense of how this topic might work. Instead, we really saw this as a local opportunity for an "artful contamination" of the Darwin celebration (Zuiderent-Jurek 2015). Some of the lack of clarity about focus and purpose became a source of tension for the group as the performance was developed, as we came to understand it differently.

\section{Workshopping Problems and Subjectivities}

The first workshop for what was to become "Living Darwin" took place in July 2008. We had 21 people in attendance over 3 days, a mix of scientists, social scientists, humanities scholars, and arts practitioners. We had not yet managed to identify community collaborators who were not already framed in the evolution/creation debate-an ongoing and highly charged political issue specific to the US. Indeed, we mention this because an Australian collaborator continually expressed her profound astonishment at the public visibility of this issue, which has essentially no play in the Australian public discourse (or in Europe).

This debate was a difficult one for us, and from the start challenged the theoretical framing of the project. We knew that we could not ignore it, but also did not want the project to be captured by the science versus religion issue. Doing so would risk a narrowing and stark polarization of the subject, which would undermine our broader goals. It would also diminish the potential transferability of the project to other (particularly international) contexts, representing a conflict between competing goals of localizing and scaling up. Two consequences emerged. First, "managing" this debate required us to monitor the types of "experts" we invited and to essentially freeze out a set of voices-in fact, the very voices that were most visible in the community and perhaps least "authorized." This raises questions about the choices we make in opening spaces for voices that are less hegemonic, in needing to silence some that are particularly loud.

The second consequence was perhaps more troubling. In the United States, sensibilities about Darwin's legacy are already so deeply shaded by debates about their significance for religion, and particularly the political manifestations and strategies around those debates, that these issues snuck back in through more subtle routes. The danger here was, are we quieting a vocal minority so that others can be heard, or are we simply reinforcing the hegemony of the scientific perspective on Darwin in ways that crowd out critiques? This became a central issue and source of tension among collaborators during development, and the resulting tension between a celebratory and a critical approach to Darwin is clearly evident in the final performance.

One particularly difficult session focused on Darwin's historical legacy. Those of us from STS approached this issue with a critical lens, but some others, particularly those on the artistic side, favored a celebratory and scientifically oriented approach. We struggled for several hours with these conflicting expectations: STS people articulating the dangers of scientific hegemony and the long histories of eugenics, scientific racism, and the naturalization of gender; the artists articulating the dangers of undermining scientific authority in the face of rising religious 
fundamentalism as well as the long overlooked beauty of an evolutionary worldview as a counter to religious inspiration and awe. And then things got personal. We broke through the abstract academic commitments, partly through play, acting, and storytelling, to contextual life stories in which these commitments have root. By moving beyond dialog to more affective, visceral, and bodily (non-verbal) interactions, we were able to break through academic habits of argumentation and abstraction, working instead through our personal and community-based experiences with these issues. We came to understand that the way through the impasse was honest storytelling, narrative, dramatic enactment, aesthetic displays, and similar non-dialogic practices that leave interpretive space for the audience.

In the end, we held three development workshops over the course of a year: "historical Darwin" (which included historians, scientists, educators, and artists focusing on the significance of Darwin for past and contemporary culture and science); "debating Darwin" (which included feminist theorists and STS scholars focusing on contemporary issues of naturalization); and "multicultural Darwin" (exploring the global and racial politics of evolution). We also held a small workshop at a local Unitarian church in which we presented some script material in an early form, accompanied by various workshop techniques. With a preliminary draft of the script in hand, the cast of 13 was chosen in May, 2009. Rehearsals were a further site of script development, and the final script was not in place until a week before the first performance-a significant source of anxiety for many of the actors.

\section{Staging Ontologies}

The full performances took place over 4 days in October, 2009, followed by a one day reprise at the Virginia Tech “Darwin Celebration" professional conference held in November. A workshop performance was also held in October at the annual meeting of the Society for the Social Studies of Science in Washington, DC. The full performance was multimedia and multi-modal, incorporating script, music, song, video, images, and dance.

Each full performance was followed by a "community dialog," a half-hour of guided discussion. Ideally, this conversation is the beginning of a broader community dialog, spilling out of the theater, about the issues raised in the play: the significance of Darwin the man and Darwin's theories in contemporary life; the relation of evolutionary theory to issues of oppression and justice; issues of naturalization and identity; the nature of scientific discovery and historical knowledge. In practice the discussions over three nights were a mix of such dialog, explicit conversation about the TWISTS model, and personal narratives about the experience of the performance (by performers and audience members).

The divergent agendas of the various collaborators were evident on stage, in both the performance and the subsequent discussion. While potentially undermining a coherent notion of a "TWISTS model," these divergent agendas nevertheless helped to reinforce the very model outlined above by challenging collaborators and audience members alike to think through multiple perspectives on Darwin and his legacy (see Living Darwin Excerpt 1). 
Living Darwin Excerpt 1: Who is Darwin?

From the performance "Living Darwin" (Kilkelly et al. 2009)

Young Questioner: Who is Darwin?

Darwin: I am!

Alisha: And Darwin was an ordinary English gentleman, born in 1809, died in 1872, with a great capacity for observation and who had traveled around the globe.

Chloe: A Victorian gentleman. And he managed, being that, to produce one of the most important ideas in the history of Western culture. (George Levine)

Gesturer: An Enlightenment thinker

Drew P: A radical thinker

Darwin: Secretary of the Geological Society

Carly and Cara simultaneously: Anti-Christ!

....Jeers and whistles from the others

Young Darwin: ... Naturalist, surveyor

Darwin: A geologist

Alisha: ... Who fell in love with fossils

Chloe: A man who thought women were weaker than men

Drew S.: An abolitionist.

Chloe: Whose work is a pillar of modern science

Drew P: Killer of meaning

Carly and Cara simultaneously: And God

...Outburst from the cast

Chloe, Alisha, Drew S, Drew P: Whose work is a pillar of modern science!

Gesturer: Okay, okay, argument. Debate. That's good. Lots of opinions, lots of questions.

\section{Creating an Agonistic Community}

On the first night the conversation focused largely on the issue of complexity: complexity of the performance with its layers of action, text, images, and movement; complexity of Darwin's work; complexity of evolutionary thought and theory in contemporary life; and complexity of 
education about a scientific theory that exceeds the science and has become mythic in our culture (see Figure 1: Learning Evolution). Complexity became a trope in this conversation that held together the myriad experiences of the developers, performers, and audience members.

The second night focused more explicitly on political aspects of evolution and Darwinism, with particular emphasis on the role and dangers of critique within the performance. This discussion was framed largely as a move away from the binaries of a religion/science debate, towards grappling with broader social and mythical dimensions of Darwinism. There was also significant discussion of the combination of text and movement in the performance as a means for exposing textual meanings to broader understandings.

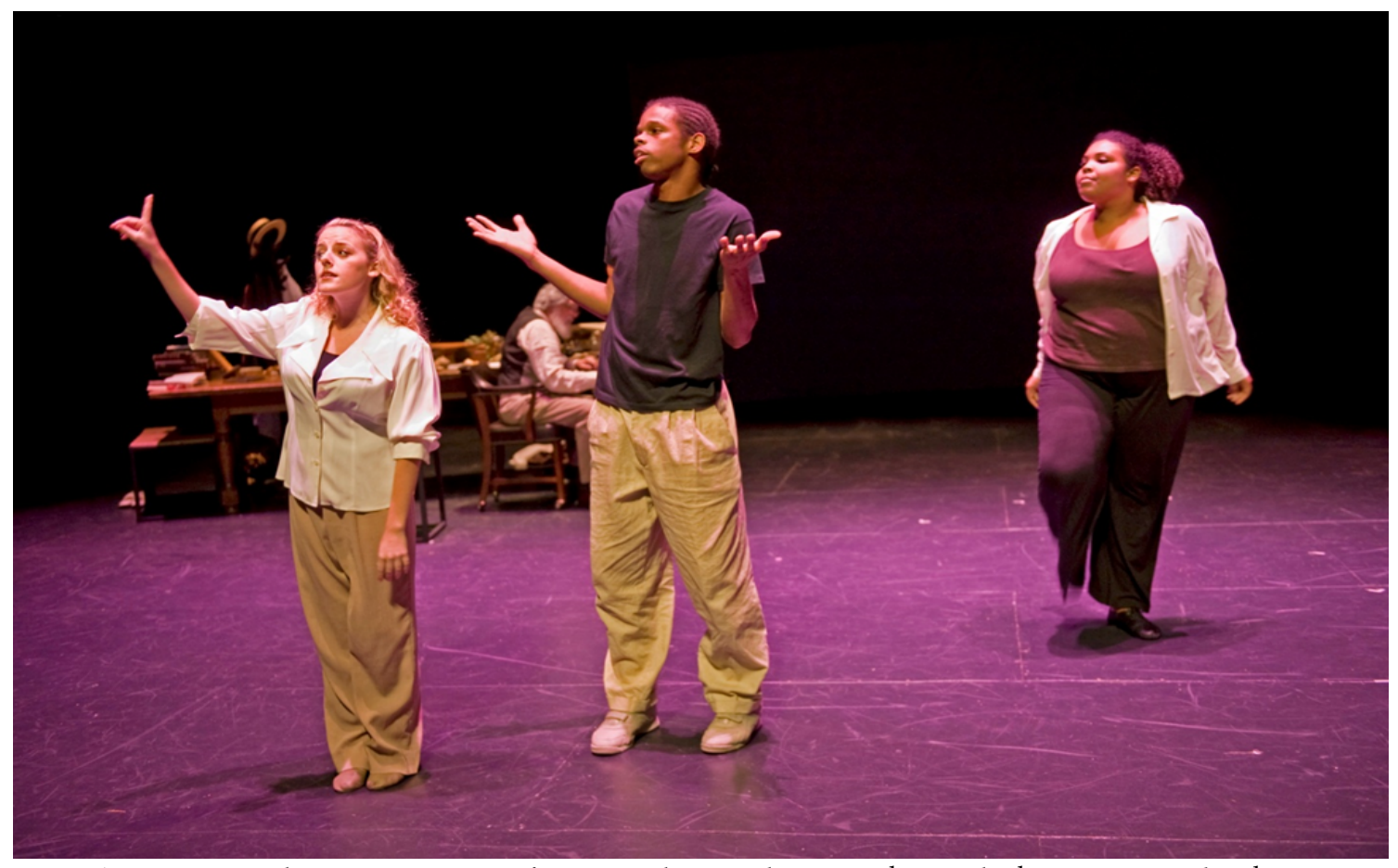

Figure 1: Learning Evolution. Integrating information about evolutionary theory-both as science and as history-was both an aesthetic challenge and source of tension within the performance group. Here, performers "teach" the audience some essential concepts in a dialogic format that allows complications and challenges to the straight-forward narrative.

The third night was the most wide-ranging, with no particular topic dominating. Two foci did seem particularly prominent, mirroring the previous night: (1) an exploration of the relation between two meanings of "Living Darwin"--the life of Darwin the man and his scientific theories during his life versus the ongoing life of his ideas within society then and now; and (2) again, the science/religion tension, which audience members felt was shown but downplayed and oversimplified. Focused attention was given to the dangers of an overemphasis on this issue.

These three dialogs provide a snapshot of possible conversations emerging from the performance in the local context of Blacksburg, Virginia. The subtext of evolution/creation 
debates was palpable throughout, but opinions varied on the significance of such debates and the treatment that they demanded. Overall, though, the broader tensions within the piece were recognized in all three nights, often as a strength, and articulated by different speakers as: a shift between the two halves of the performance; ambivalences in the meanings of the title; statements about the relations of the science and social impacts; or alternating statements between the beauty and significance of Darwin's words and theories versus the social consequences of Darwinism more broadly.

\section{Reflection}

The relation between the theory and practice of TWISTS is complex. The theory motivates the activities of performance development and the performances themselves, but these practices also push back, highlighting the difficulty of achieving this ideal.

Many of the shortcomings of the TWISTS model can be located in practicalities of time, money, personnel, and skills. The theory serves as a horizon, and a check on familiar routines of thought and practice, rather than a practical framework for action. Issues of scale-up and followthrough were particularly difficult. Despite early plans, we were unable to bring the performances "on the road," an expensive and complicated proposition requiring significant time from collaborators and actors.

Furthermore, our use of student actors in performances was both a strength and a problem. On the one hand, students bring renewed strength and energy to every cycle of performance, expand the reach of the project, and give the project credibility as an educational endeavor. On the other hand, traditional performance expectations and academic cycles are such that it is very difficult to get these actors to continue performing and participating on an ongoing basis after the initial performance-dialog. Yet, because the project collaborators are largely nonactors, it is difficult to simply internalize the performance aspects of the project within the core participants.

In addition, the three conversations of the Living Darwin performances, limited to 30 minutes each, points to a particular weakness of TWISTS: the performances, and even workshops, are highly time bound and hope to create change by throwing out ideas, images, and experiences, but it has long been recognized that individual and community change activity is only effective when accompanied by ongoing relationships and institution building (Checkoway 1997). TWISTS could only hope to reach its broader goal of community activation through longterm institutionalization and ongoing engagement in these communities and our failed attempts to secure a multiyear grant made this nearly impossible. TWISTS fell apart just as we were attempting to scale up.

Nevertheless, TWISTS can continue to serve as a model for thinking through the four key concepts around which it was built: performance, activation, agonism, and expertise.

The critical performance model of TWISTS emphasizes the disruption of hierarchies through the integrated script production and rehearsal phases, with the performers themselves further devising scenes that describe their experiences. In theory, such practices are also used in 
the final performance itself, although "Living Darwin" did mostly retain a traditional audience/actor divide until the post-performance discussion, where at least some space was open for substantial disruption. For example, when audience members were asked to share their thoughts about the performance, several actors' representations of Darwin's works and legacy were openly challenged by some audience members who offered alternative interpretations, thereby expanding the range of perspectives encountered at the stage event.

Performance also emphasizes the non-dialogic aspects of the project-the ways that aesthetics, art, and play served as crucial sites for both working through group dynamics and tensions, and presenting those tensions productively to audiences. The interpretive flexibility and narrative personalization of performance created a space within which audiences could more readily embody alternative perspectives and experiences. This was starkly evident during audience discussions of the complex and ambivalent meanings conveyed by combining text and movement in the performance.

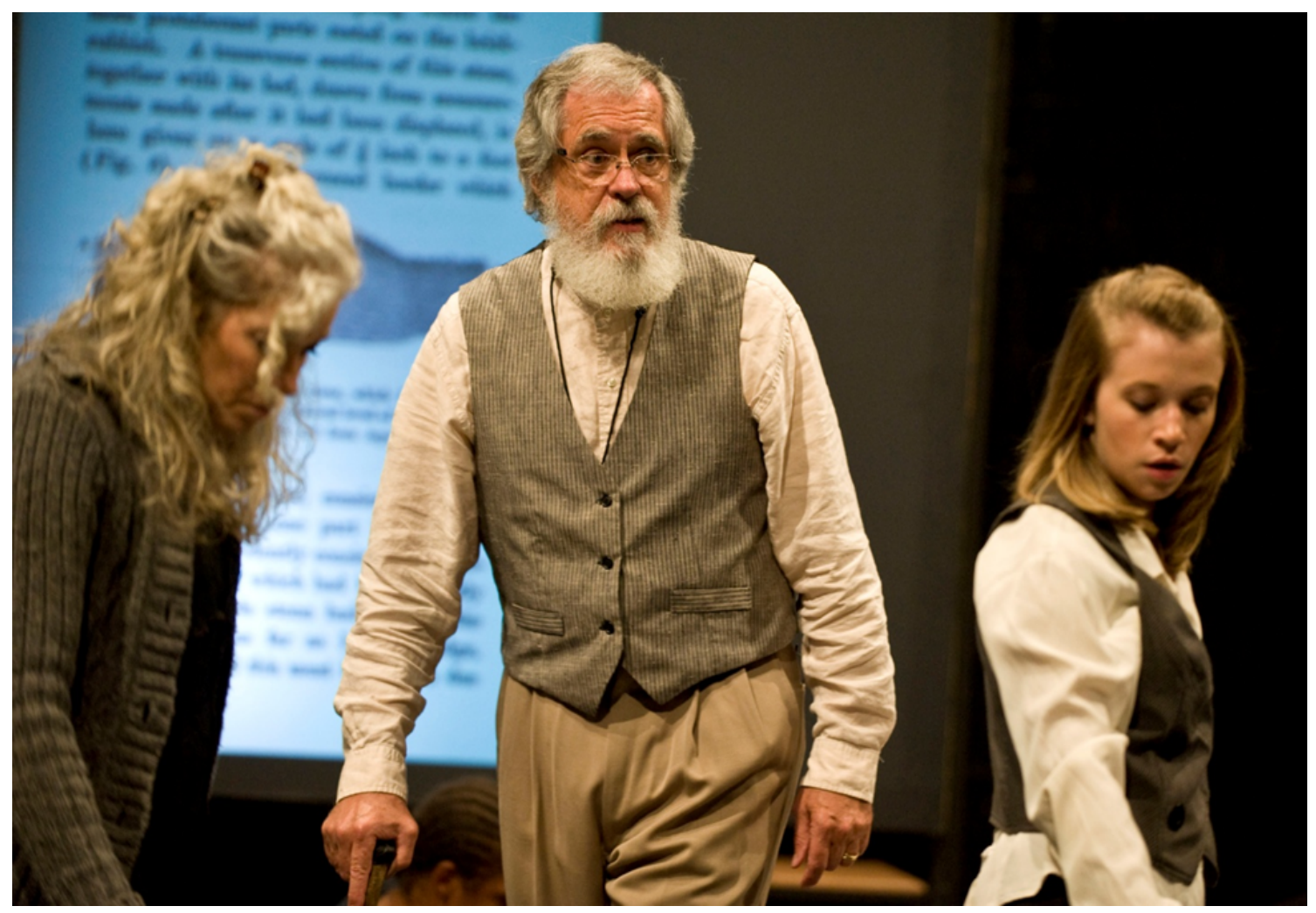

Figure 2: Darwin: The Man. Darwin was physically present throughout the performance, sometimes working quietly at his desk, often interjecting internal thoughts, sometimes speaking directly to questions of theory and context. Older Darwin reflected back on his life; young Darwin grappled with the meaning of his findings. This set of devices acknowledged the simultaneous presence of Darwin, the man, and Darwin, the metaphor and myth in contemporary evolutionary discourse and practice. 
Activation also served as a structuring principle more than an actual outcome. Articulated as the rather simple goal of "bringing perspectives, discourses, and issues into public dialog-getting people to think publicly rather than just privately about an issue and thus spurring community-based action," this goal had limited success. While workshop and performance experiences and dialogs were wide-ranging, without institutionalization and long-term followup, the goal of community action was more hopeful than realistic. It is interesting to note that, based on proposal reviewer comments, our failure to secure long-term funding had much to do with our conscious decision not to pursue explicit policy goals, but to instead focus on community-based cultural politics-itself an undervalued goal in STS and educational engagement.

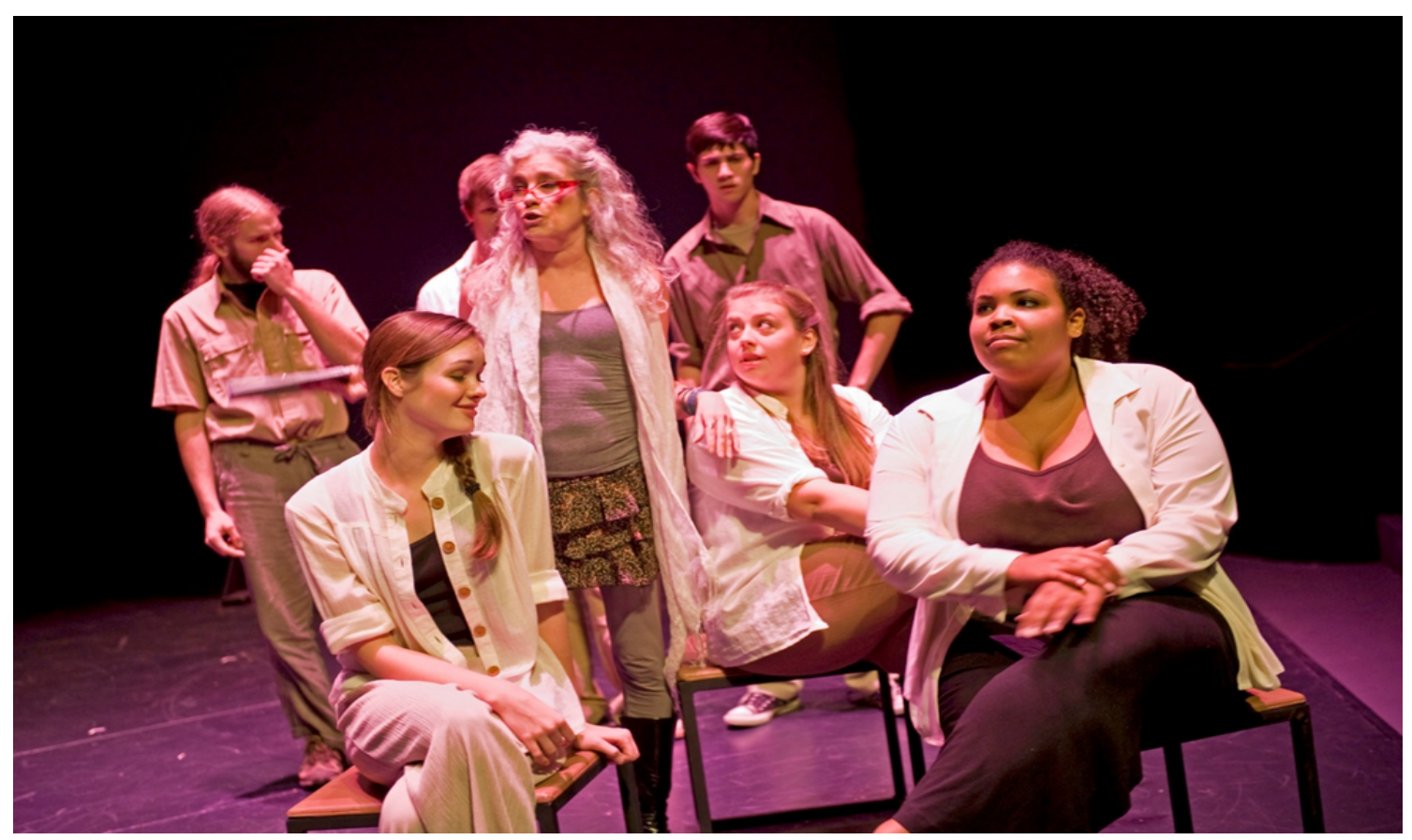

Figure 3: Natural Women. The naturalization of gender roles through evolutionary discourse was explored through discussions between female cast members on their self-perceptions and roots of their relations with the men. The Aretha Franklin song "A Natural Woman" sung by the whole cast provided some comic relief.

Perhaps the greatest long-term impacts, therefore, were experienced by those working on the project itself--collaborators, development workshop participants, and the cast and crew (including a number of students).

The goal of agonistic engagement was a clearer success. STS engaged, on the ground, requires us to collaborate with many people with different commitments. Within "Living Darwin," there were struggles over: 1 . the meaning of "living," a purposefully ambiguous word that invokes variously a set of daily practices, a mindset, or a memory; 2 . Darwin as a metaphor 
and Darwin as a man; and 3. "Living Darwin" as a political or artistic expression (see Figure 2: Darwin: the Man). Many of these struggles coalesced in a central tension in the project between celebration and criticism.

On the one hand were fears that an overly critical stance towards Darwin: 1. plays into religious fundamentalist critique, and thus regressive politics; 2 . unduly downplays the importance of Darwin's role in contemporary life and thought; and 3. risks fundamentally missing the sheer aesthetic and intellectual brilliance of Darwin's extensive corpus of work. This perspective influenced a significant portion of the performance as built around a reading and visualization of Darwin's travels, words, and observations - of earth worms and vegetable mould (Darwin 1881); that is, an exploration of historical Darwin and his legacy for the biology, aesthetics, and knowledge of contemporary life (Carroll 2005; Darwin 1859; Keynes 2001).

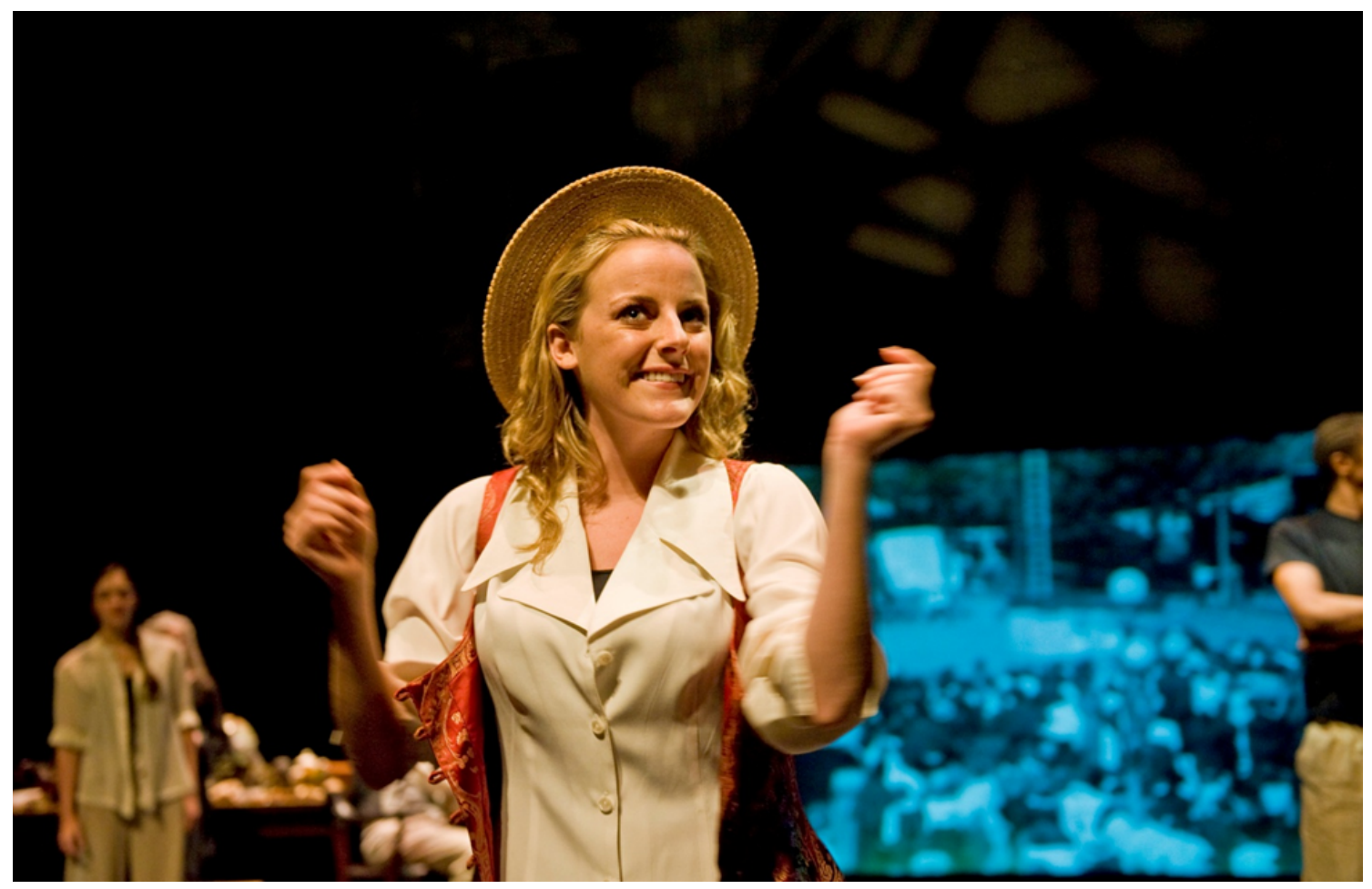

Figure 4: Eugenics Road Show. The history of eugenics had a prominent place in the second act, through both a carnivalbased "fitter family contest" and individual narratives of eugenic depredations. Tension within the group was reflected in ambivalence about whether Eugenics grew directly out of Darwinian theory or was a later "misreading" of evolutionary lessons.

On the other hand were a set of concerns that such a focus on historical Darwin, and particularly Darwin, the man, risks valorizing the now-dominant frames of evolution and naturalization with its legacies of explicit and implicit, often racist, sexist, classist, and otherwise 
regressive, socio-biology (Haraway 1992; Jackson and Weidman 2004; McCaughey 2008) (See Figure 3: Natural Women and Figure 4: Eugenics Road Show).

These tensions remained in the performance, and in the subsequent dialogs, in ways that were themselves productive (see Living Darwin excerpt 2). Rather than needing ourselves to fully resolve them, they became part of the ground upon which public activation could be imagined. Such tensions, unresolvable even among a small group of collaborators, who nevertheless came to respect each other's situated commitments, thus represent an agonistic success.

Living Darwin Excerpt 2: competition, cooperation, and grandeur From “Living Darwin" (Kilkelly et al. 2009):

Young Questioner (YQ): Things are born, things die, we die. We don't live forever. Is life all about survival? Is it all about extinction? If human beings become extinct, if nobody survives, have we failed? And if we're connected to bacteria, connected to fish, stars, stardust, everything, do we live in that? Being netted together?

Drew P.: The way I see it, if you are strong, you survive; if you are weak, you die. Capitalism has survived and prospered because we are all selfish anyway, just selfish genes maximizing our wins. Capitalism just fits who we are. Primates. Nature, violence, war, plunder. Dominance and competition.

YQ: You always look at Chimps and Baboons But what about cooperation? That's evolutionary too. And caring and giving and loving. What about bonobos? They're matriarchal - they're cooperative.

Drew P: Cooperation and competition are the same, just different competitive strategies.

Yeah, you know, female chimps that have sex with males. Sex is the basis for kinship and chimp society. It's not really different for people, is it? That's what traditional families are all about.

Chloe: That's just not true. Human culture was driven by female ingenuity, not male dominance. Why do you think humans are weaker but smarter than chimps? Females select mates with less aggressive features, who can be more sociable and not chase off those who could help them.

Gathering, female work, was the key adaptation that led to tool development, like baby carriers, baskets, and digging sticks. Female discovery also led to the need to cooperate and communicate more effectively. Dominance is not the key to cooperation, mutual support is.

Drew P.: The meaning of evolution is what you can get for you and yours. Dog eat dog.

Gesturer: Stories, stories. So many stories we tell about monkeys to justify our own ways of thinking. Monkeys tell us nothing about who we are. Whether we evolved from them or not, it's irrelevant. We are free to choose to dominate or cooperate. Fierce competition or social justice. Capitalism or socialism. Evolutionary stories support them all, and none of them convincingly.

Alisha: I don't think evolution is just any story. There's so much more that we know, that supports Darwin.

Cast Variously: fossils, transitional forms, DNA, genomes, atomic theory, quantum physics, microbiology, nanotechnology, etc. all evo-devo

Alisha: But what matters for me is that I'm an only child. And my husband is an only child. We feel pressure to have kids-You're an only child-never explicit, but there. It's so there. We're 
married and we're only children and neither of us want to have kids. We end up feeling like we're killing our parents. Like we are literally killing our parents. Like our lives don't have meaning if we don't reproduce. If Darwin is right, is there no meaning in our lives? In anybody's?

YQ : But I think something about all of this is really important. It's beautiful, isn't it? So much we can see and know about. And more we can't imagine.

Darwin: There is grandeur in this view of life, with its several powers, having been originally breathed into a few forms or into one; and that, whilst this planet has gone cycling on according to the fixed laws of gravity, from so simple a beginning endless forms most beautiful and most wonderful have been, and are being evolved.

\section{Conclusion: Collaborative STS on the Ground}

The creation of the "Living Darwin" performance serves as a showcase for and helps to crystallize the many tensions that run through TWISTS, but also highlights its potential. It is a site for exploring simultaneously controversial technoscience, public engagement with science and technology, interdisciplinary collaboration, and engaged STS.

We began this paper by asking, "can a University-based, agonistic performance model succeed in activating a community to grapple with complex S\&T issues? Or, put more simply, does TWISTS serve a meaningful function as public engagement beyond the aesthetic enjoyment of participants? And, does it offer a model of PEST that hues more closely to that movement's stated ideals?"

"Living Darwin" enacts an engaged STS in two distinct senses: through collaboration and through performance. Project collaboration involves the negotiation of an STS sensibility with others who are more committed to a realist (usually scientific) ontology, in a difficult negotiation of difference (Fortun and Cherkasky 1998). Negotiating conflicting sensibilities about science and technology challenged us to think about what is most important in this project, and to articulate what is at stake for each participant.

Both the STS practitioners and the other collaborators became attuned to and animated by the polyphony of perspectives around controversial science and technology, in this case Darwin's work and his legacy. In order for the collaboration to proceed, participants had to reflexively engage with this polyphony and receive challenges to their own perspectives with an attitude of "critical responsiveness" (Connolly 2008). The tensions around the Darwin project, as discussed above, raised new questions about what it means to represent scientific controversy to public audiences. While we had confronted divergent positions in previous projects (for example, in "Nuclear Power Play" we addressed the place of nuclear power in the future mix of energy sources), those projects involved broader ideological and strategic agreement among direct participants that allowed us to explore the range of positions without ourselves getting caught up in internal conflict.

The shared commitment to the project helped collaborators keep their individual commitments to the topic in check. Thus, as we each encountered people in the project with other stakes we reflected on, articulated, and shifted our own stakes. In the end, the core TWISTS 
organizers-specifically the authors of this paper-prioritized polyphonous engagement, the idea of presenting multiple perspectives even if those perspectives were personally uncomfortable, over a particular message that might tear the larger group apart. As long as each contributor's cherished positions (and positions brought into the group through other sources) were honestly represented, with care, respect, and nuance, the members of the group were able to temper their strong objections.

This experience thus reinforced and solidified several key features of the project. First, critical responsiveness can be achieved within a group when other mechanisms of solidarity are in place to produce trust or at least interpersonal respect. But such a situation is not given and must be consciously cultivated through practices of intimacy and vulnerability. Performance is thus key to success in this sense: in our case, dialog alone was unable to bridge our divides but non-dialogic movement, storytelling, and "serious play" were key to presenting and representing divergent perspectives.

We thus posit this aspect of the project as a clear success. This project could have easily fallen into sustained homage to Darwin, thus reinforcing a kind of scientific hegemony around evolution. There were strong voices in our group pushing for that approach. But the group's agonistic commitments and practices provided continual openings for challenges and the opportunity to surface hidden and underplayed voices.

Furthermore, such practices of agonism within the group facilitated agonistic engagement with the audience. Audiences felt the tensions within the performances, and those tensions became an explicit focus of the after-performance discussions. Rather than papering over our conflicting commitments and positions, as a consensus position might have done, the spillover of their irreconcilability was productive, with the presentation of agonism itself as important as the content of the piece.

Thus, the second form of engagement, those moments in the public dialog in which fundamental questions of meaning and knowledge were framed by audience members, make the project seem more feasible as a long-term endeavor. Here engaged STS happens as the project steps outside of its collaborative confines and enrolls new participants. These new participants have ideally been activated at the performance site by being confronted with questions about dominant viewpoints. They carry the potential to bring this activation to communities previously unreached through the first form of engaged STS (direct collaboration).

In contemplating the engagement of TWISTS, this paper seeks to make a few modest interventions within the PEST literature. In relation to theory, it contributes to a small PEST literature on non-policy and non-education engagement, by focusing on community perspectives and transformation. Our approach, perhaps, comes closest to discussions of citizen capacity (Selin 2016) and mutual learning (Lehr et al. 2007) within the PEST literature. To these literatures, it contributes a sustained commitment to agonism--a valuing of encounter, discomfort, and the disruption of hegemonic positions instead of either consensus or authoritative frames. The avoidance of specific policy goals and learning outcomes provides the space for such an approach, although it does contribute to ongoing development of PEST through "contesting impacts and outcomes" (Irwin et al. 2013). 
TWISTS also provides a strong model for accounting for the multiplicity of expertise. Mobilizing diverse expertise has been a central tenet of many previous public engagement activities, but TWISTS provides a specific model for incorporating and balancing such expertise. Rather than downplaying or ignoring expertise, TWISTS works to harness and elevate undervalued and silenced voices as much as authorized voices within performance development. Our experts included scientists, social science and humanities scholars, and arts practitioners, but also community members, performance contributors, and student actors. In doing so, it locates scientific and technical knowledge as one set of perspectives among many.

This goal is not, however, simple or risk free. It names instead the most difficult ongoing struggle within the project, and one that was never fully resolved. This should not surprise STS scholars who have long studied struggles between hegemonic and resistant forms of knowledge and authority: the workshops and final performances enacted tensions between scientific hegemony as both a source of dominant power and a bulwark against illiberalism.

In relation to practice, TWISTS remains compatible with a dialogic model of PEST, but moves definitively beyond that, recognizing that affective and corporeal engagements with issues are central and crucial parts of community activation and encounter (Davies 2014). TWISTS thus pushes against the bias in contemporary political theory and engagement practice towards verbal, dialogic action. Our performances contain a lot of dialog, but also music, dance, and visual arts, as well as explicit attempts to juxtapose these elements to produce a non-logical affective experience. We offer TWISTS performance theory as a model for including the dialogic and non-dialogic together in community interaction around science and technology issues. While TWISTS neither provides a perfect model for agonistic community activation nor can be considered a clear success, even in its own terms, the TWISTS model of STS engaged performance offers new approaches and transferable lessons to a new kind of public engagement.

\section{Author Biography}

Saul Halfon is Associate Professor of Science, Technology, and Society at Virginia Tech. He works in the political sociology of science and technology, especially food governance, the politics of demography and population, and the international politics of food and risk. He also has an ongoing interest in public engagement efforts. He served as co-Director of TWISTS and the Choices and Challenges public engagement program.

\section{Author Biography}

Cora M. Olson currently works as an engaged Instructional faculty member at Virginia Tech and the Virginia Tech Carilion School of Medicine. Her instructional practices focus on disrupting the dominant narratives of medicine through intersectional critiques of medical education techniques, biomedical practices, and biomedical constructions of ethical theory. Her research has two foci: one on the role of pedagogy as intervention in medical and pre-medical education and 
the other on the regulation and construction of athlete bodies through biomedical research. Cora served as a long term Graduate Assistant for TWISTS.

\section{Author Biography}

Ann Kilkelly is Professor Emeritus of Women's Studies and Theatre Arts at Virginia Tech. She is a teacher of theater, women's studies, historical dance forms, and community engagement. She has published on community-based performance and has tap-danced in a range of professional and local venues. She was TWISTS' artistic director.

\section{Author Biography}

Dr. Jane Lehr is the Director of Student Research and a professor in Ethnic Studies and Women's, Gender \& Queer Studies at California Polytechnic State University, San Luis Obispo. She is Faculty Director of the California State University Louis Stokes Alliance for Minority Participation (LSAMP) in STEM Program at Cal Poly. Her teaching and research focus on the complex relationships between gender, race, culture, science, technology, and education. Her PhD is in Science \& Technology Studies and Women's Studies at Virginia Tech. She was the founder and co-director of TWISTS.

\section{Acknowledgements}

We wish to thank the dozens of collaborators, performers, and workshop participants in the TWISTS project over its 10-year run. Also, Gary Downey and anonymous reviewers, as well as the journal editors, provided helpful comments on this and earlier drafts. The TWISTS project was initially supported by a grant from Virginia Tech's Institute for Society, Culture, and Environment.

\section{References}

Bicât, Tina, and Chris Baldwin, eds. 2002. Devised and Collaborative Theatre: A Practical Guide. Ramsbury, Marlborough, UK: Crowood P Ltd.

Boal, Augusto. 1979/1982. The Theatre of the Oppressed. New York: Urizen Books/Routledge.

Boal, Augusto. 1992. Games for Actors and Non-Actors. New York: Routledge.

Boler, Megan. 1999. Feeling Power: Emotions and Education. New York: Routledge.

Carroll, Sean. 2005. Endless Forms Most Beautiful: The New Science of Evo Devo and the Making of the Animal Kingdom. New York: W. W. Norton \& Company.

Chambers, Samuel A. 2001. "Language and Politics: Agonistic Discourse in The West Wing." December 11. http://ctheory.net/ctheory_wp/language-and-politics-agonisticdiscourse-in-the-west-wing $/$. 
Checkoway, Barry. 1997. "Core Concepts for Community Change." Journal of Community Practice 4 (1):11-29.

Cless, Downing. 1996. "Eco-Theatre USA: The Grassroots is Greener." The Drama Review 40(2):79102.

Cohen, Benjamin R., and Wyatt Galusky. 2010. "Guest Editorial for Special Issue: Embodying STS." Science as Culture 19 (1):1-14.

Connolly, William E. 2005. Pluralism. Durham, NC: Duke University Press.

Connolly, William E. 2008. William E. Connolly: Democracy, Pluralism and Political Theory. Edited by Samuel Allen Chambers and Terrell Carver. London/New York: Routledge.

Darwin, Charles. 1859. The Origin of Species: By Means of Natural Selection or the Preservation of Favoured Races in the Struggle for Life. First ed. London: John Murray. http://darwinonline.org.uk/converted/pdf/1859_Origin_F373.pdf.

Darwin, Charles. 1881. The Formation of Vegetable Mould through the Action of Worms, with Observations on their Habits. London: John Murray. http://darwinonline.org.uk/converted/pdf/1881_Worms_F1357.pdf.

Davies, Sarah, Ellen McCallie, Elin Simonsson, Jane L. Lehr, and Sally Duensing. 2009. "Discussing Dialogue: Perspectives on the Value of Science Dialogue Events that Do Not Inform Policy." Public Understanding of Science 18 (3):338-353.

Davies, Sarah R. 2014. "Knowing and Loving: Public Engagement beyond Discourse." Science $\mathcal{E}$ Technology Studies 27 (3):90-110.

Delborne, Jason, Jen Schneider, Ravtosh Bal, Susan Cozzens, and Richard Worthington. 2013. "Policy Pathways, Policy Networks, and Citizen Deliberation: Disseminating the Results of World Wide Views on Global Warming in the USA." Science and Public Policy 40:378392. doi: $10.1093 /$ scipol/scs124.

Delborne, Jason A. 2011. "Constructing Audiences in Scientific Controversy." Social Epistemology 25 (1):67-95. doi: 10.1080/02691728.2010.534565.

Dolan, Jill. 1988. The Feminist Spectator as Critic. Ann Arbor, Mich: UMI Research Press.

Downey, Gary L. 2009. "What is Engineering Studies for? Dominant Practices and Scalable Scholarship." Engineering Studies 1 (1):55-76.

Dryzek, John S. 2000. Deliberative Democracy and Beyond: Liberals, Critics, Contestations. Oxford Political Theory series. Oxford: Oxford University Press.

Einsiedel, Edna, and Deborah L. Eastlick. 2000. "Consensus Conferences as Deliberative Democracy: A Communications Perspective." Science Communication 21 (4):323-343.

Einsiedel, Edna, Erling Jelsøe, and Thomas Breck. 2001. "Publics at the Technology Table: The Consensus Conference in Denmark, Canada, and Australia." Public Understanding of Science 10 (1):93-98.

Elam, Mark, and Margareta Bertilsson. 2003. "Consuming, Engaging and Confronting Science: The Emerging Dimensions of Scientific Citizenship." European Journal of Social Theory 6 (2):233-251. 
Evans, Robet, and Harry Collins. 2008. "Expertise: From Attribute to Attribution and Back Again?" In The Handbook of Science and Technology Studies, edited by E. Hackett, O. Amsterdamska, M. Lynch and J. Wajcman, 609-30. Cambridge, MA: MIT Press.

Ezrahi, Yaron. 1990. The Descent of Icarus: Science and the Transformation of Contemporary Democracy. Cambridge, MA: Harvard University Press.

Fisher, E. and R. L. Mahajan. 2010. "Embedding the Humanities in Engineering: Art, Dialogue, and a Laboratory." In Trading Zones and Interactional Expertise: Creating New Kinds of Collaboration, edited by M. E. Gorman. Cambridge, MA: MIT Press.

Fisher, E., R. L. Mahajan, and C. Mitcham. 2006. "Midstream Modulation of Technology: Governance from Within." Bulletin of Science, Technology \& Society, 26 (6):485-496.

Fortun, Kim, and Todd Cherkasky. 1998. "Counter-expertise and the Politics of Collaboration." Science as Culture 7 (2):145-172.

Guston, David H. 1999. "Evaluating the First U.S. Consensus Conference: The Impact of the Citizens' Panel on Telecommunications and the Future of Democracy." Science, Technology \& Human Values 24 (4):451-482.

Haraway, Donna. 1988. "Situated Knowledges: The Science Question in Feminism and the Privilege of Partial Perspective." Feminist Studies 14 (3):575-599.

Haraway, Donna. 1991. Simians, Cyborgs, and Women: The Reinvention of Nature. New York: Routledge.

Haraway, Donna. 1992. Primate Visions: Gender, Race and Nature in the World of Modern Science. London: Verso.

Harding, Sandra. 1993. "Rethinking Standpoint Epistemology: What is "Strong Objectivity"?" In Feminist Epistemologies edited by L. Alcoff and E. Potter, 49-82. New York: Routledge.

Harding, Sandra. 2006. Science and Social Inequality: Feminist and Postcolonial Issues. Champaign, IL: University of Illinois Press.

Heddon, Deirdre, and Jane Milling. 2006. Devising Performance: A Critical History. Basingstoke, UK/New York: Palgrave Macmillan.

Holden, Constance. 2002. "Random Samples: From PUS to PEST." Science 298 (5591):49.

Hilgartner, Stephen. 2000. Science on Stage: Expert Advice as Public Drama. Palo Alto, CA: Stanford University Press.

Irwin, Alan. 2001. "Constructing the Scientific Citizen: Science and Democracy in the Biosciences." Public Understanding of Science 10 (1):1-18.

Irwin, Alan. 2014. "From Deficit to Democracy (Re-Visited)." Public Understanding of Science 23 (1):71-76. doi: 10.1177/0963662513510646.

Irwin, Alan, Torben Elgaard Jensen, and Kevin E. Jones. 2013. "The Good, the Bad and the Perfect: Criticizing Engagement Practice." Social Studies of Science 43 (1):118-135.

Irwin, Alan, and Brian Wynne, eds. 1996. Misunderstanding Science? The Public Reconstruction of Science and Technology. Cambridge: Cambridge University Press.

Jackson, John P., and Nadine M. Weidman. 2004. Race, Racism, and Science: Social Impact and Interaction. Santa Barbara, CA: ABC-CLIO. 
Jasanoff, Sheila. 2004. "Science and Citizenship: A New Synergy." Science and Public Policy 3 (1/2):90-94.

Joss, S., and J. Durant. 1995. Public Participation in Science: The Role of Consensus Conferences. London: London Science Museum.

Keynes, Randal. 2001. Annie's Box: Charles Darwin, His Daughter and Human Evolution. New York: Fourth Estate.

Kilkelly, Ann, with Collaborators, Carol Burch-Brown, and Celeste Miller. 2009. “Living Darwin." Blacksburg: Virginia Tech.

Kleinman, Daniel Lee, and Katie Vann. 2016. "Ongoing Engagement of Science, Technology and Society." Engaging Science, Technology, and Society 2(2):1-2. doi: 10.17351/ests2016.95.

Kurath, Monika, and Priska Gisler. 2009. "Informing, Involving or Engaging? Science Communication, in the Ages of Atom-, Bio- and Nanotechnology." Public Understanding of Science 18 (5):559-573.

Leach, Melissa, and Ian Scoones. 2006. The Slow Race: Making Technology Work for the Poor. London: DEMOS.

Lehr, Jane L. 2006. "Social Justice Pedagogies and Scientific Knowledge: Remaking Citizenship in the Non-Science Classroom." Ph.D. Dissertation, Science and Technology Studies, Virginia Tech.

Lehr, Jane L., E. McCallie, S. Davies, B. R. Caron, B. Gammon, and S. Duensing. 2007. "The Value of "Dialogue Events" as Sites of Learning: An Exploration of Research and Evaluation Frameworks." International Journal of Science Education 29 (12):1467-1487.

Lengwiler, Martin. 2008. "Participatory Approaches in Science and Technology: Historical Origins and Current Practices in Critical Perspective." Science, Technology \& Human Values 33(2):186-200.

Leonard, Robert H., and Ann Kilkelly. 2006. Performing Communities: Grassroots Ensemble Theaters Deeply Rooted in Eight U.S. Communities. Oakland, CA: New Village Press.

Liberatore, Angela, and Silvio Funtowicz. 2000. "'Democratising' Expertise, 'Expertising' Democracy: What Does This Mean, and Why Bother?" Science and Public Policy 30 (3):146150.

Mayer, I., and J. Geurts. 1999. "Consensus Conferences as Participatory Policy Analysis: A Methodological Contribution to the Social Management of Technology." In The Social Management of Genetic Engineering, edited by P. Wheale, R. von Schomburg, and P. Glasner, 279-301. Aldershot: Ashgate.

McCallie, Ellen, Larry Bell, Tiffany Lohwater, John Falk, Jane Lehr, Bruce Lewenstein, Cynthia Needham, and Ben Wiehe. 2009. "Many Experts, Many Audiences: Public Engagement with Science and Informal Science Education." A CAISE Inquiry Group Report. Washington, DC: CAISE.

McCaughey, Martha. 2008. The Caveman Mystique: Pop-Darwinism and the Debates Over Sex, Violence, and Science. New York: Routledge. 
McKibben, Bill. 2005. "Imagine That: What the Warming World Needs Now is Art, Sweet Art." Grist April 25. Accessed June 7, 2010. https://grist.org/article/mckibben-imagine/.

Mermikides, Alex, and Gianna Bouchard. 2016. Performance and the Medical Body. London: Bloomsbury Methuen Drama.

Mouffe, Chantal. 2000. The Democratic Paradox. London/ New York: Verso.

Mulvey, Laura. 1975. "Visual Pleasure and Narrative Cinema." Screen 16 (3):6-18.

Mutz, Diana Carole. 2006. Hearing the Other Side: Deliberative Versus Participatory Democracy. Cambridge/New York: Cambridge University Press.

Nowotney, H., Scott, and M. Gibbons. 2001. Re-thinking Science: Knowledge and the Public in an Age of Uncertainty. Cambridge: Polity.

Oddey, A. 1996. Devised Theatre. New York/Oxford: Routledge.

Odegaard, M. 2003. "Dramatic Science. A Critical Review of Drama in Science Education." Studies in Science Education 39(1):75-102.

Pearson, G., and B. Holligan. 2002. "Using Drama to Communicate Science." Annual Public Communication of Science and Technology (PCST-7) Conference.

Pestre, Dominique. 2008. "Challenges for the Democratic Management of Technoscience: Governance, Participation and the Political Today." Science as Culture 17 (2):101-119.

Rip, Arie, T. J. Misa, and J. Schot. 1995. Managing Technology in Society: The Approach of Constructive Technology Assessment. London: Pinter.

Rohd, Michael. 1998. Theatre for Community Conflict and Dialogue: The Hope Is Vital Training Manual. Portsmouth, NH: Heinemann Drama.

Rowe, G., and L. J. Frewer. 2005. "A Typology of Public Participation Mechanisms." Science, Technology, \& Human Values 30 (2):251-90.

Sainsbury, Lord, and Mike Dexter. 2000. Science and the Public: A Review of Science Communication and Public Attitudes to Science in Britain. London: A Joint Report by the Office of Science and Technology and the Wellcome Trust.

Schechner, Richard. 1988. Performance Theory. Revised and expanded. New York: Routledge.

Schutzman, Mady, and Jan Cohen-Cruz, eds. 1994. Playing Boal: Theatre, Therapy, Activism. New York: Routledge.

Schutzman, Mady, and Jan Cohen-Cruz. 2006. A Boal Companion: Dialogues on Theatre and Cultural Politics. New York: Routledge.

Sclove, Richard. 2000. "Town Meetings on Technology: Consensus Conferences as Democratic Participation." In Science, Technology, and Democracy, edited by D. L. Kleinman. Albany, NY: State University of New York Press.

Sclove, Richard. 2010. "Reinventing Technology Assessment: a 21st Century Model." Woodrow Wilson International Center for Scholars. https:/ / ecastnetwork.files.wordpress.com/2019/03/reinventingtechnologyassessment.p df.

Selin, Cynthia, Kelly Campbell Rawlings, Kathryn de Ridder-Vignone, Jathan Sadowski, Carlo Altamirano Allende, Gretchen Gano, Sarah R. Davies, and David H. Guston. 2016. "Experiments in Engagement: Designing Public Engagement with Science and 
Technology for Capacity Building." Public Understanding of Science 26 (6):634-649. doi: $10.1177 / 0963662515620970$.

Shepherd-Barr, Kirsten. 2006. Science on Stage: from Doctor Faustus to Copenhagen. Princeton: Princeton University Press.

Sullivan, John, Sharon Petronella, Edward Brooks, Maria Murillo, Loree Primeau, and Jonathan Ward. 2008. "Theatre of the Oppressed and Environmental Justice Communities: A Transformational Therapy for the Body Politic." Journal of Health Psychology 13 (2):166-179.

Tselfes, Vasilis, and Antigoni Paroussi. 2009. "Science and Theatre Education: A Crossdisciplinary Approach of Scientific Ideas Addressed to Student Teachers of Early Childhood Education." Science E Education 18 (9):1115-1134. doi: 10.1007/s11191-0089158-2.

Wilsdon, J., and R. Willis. 2004. See-Through Science: Why Public Engagement Needs to Move Upstream. London: DEMOS. Open Access Book.

Woodhouse, Edward, David Hess, Steve Breyman, and Brian Martin. 2002. "Science Studies and Activism: Possibilities and Problems for Reconstructivist Agendas." Social Studies of Science 32 (2):297-319.

Zuiderent-Jerak, Teun. 2015. Situated Intervention: Sociological Experiments in Health Care. Cambridge, MA: MIT Press.

Zuiderent-Jerak, Teun, and Casper Bruun Jensen. 2007. "Editorial Introduction: Unpacking 'Intervention' in Science and Technology Studies." Science as Culture 16 (3):227-235. 